\title{
The Effect of Implicitation \& Explicitation Strategies on the Acceptance of Two Different Farsi Translations of George Orwell's Animal Farm
}

\author{
Zhilla Sepehri \\ MA in Translation Studies, Department of English \\ Parand Branch, Islamic Azad University, Tehran, Iran \\ Razieh Eslamieh (Corresponding author) \\ Assistant Professor, Department of English \\ Parand Branch, Islamic Azad University, Parand, Iran \\ E-mail: eslami_paranduniv@yahoo.com
}

Received: July 21, 2021 Accepted: September 7, $2021 \quad$ Published: September 24, 2021

doi:10.5296/ijl.v13i5.18878

URL: https://doi.org/10.5296/ijl.v13i5.18878

\begin{abstract}
Explicitating and implicitating are among the significant facets of texts in Translation Studies. They vary across languages in terms of the way and process of transferring into another language. This research presents a study of explicitation and implicitation in translation. Explicitating and implicitating shifts were manually identified in a corpus of English and their translations in presian. Explicitating and implicitating Shifts were classified according to Vahedi Kia's (2011) framework. The study tries to explore the percentage of the usage of explicitations and implicitating in two different translations of George Orwell's Animal Farm. The main aim of the study was to specify the relation and the Effect of implicitation \& explicitation strategies on the acceptance of two different farsi translations of George Orwell's Animal Farm. Unlike most other studies of explicitation in translation, the present study did not depart from the assumption of a 'translation-inherent', universal process of explicitation (cf. Blum-Kulka's Explicitation Hypothesis). Rather, the prediction underlying the study was that every instance of explicitation (and implicitation) can be explained as a result of lexicogrammatical and/or pragmatic factors. This analysis has made it possible to compile a list of factors that regularly lead translators to explicitate or implicitate. The factors explain why implicitations are often outnumbered by the corresponding explicitations.
\end{abstract}

Keywords: Animal Farm, Explicitation, Implicitating, Klaudy, Vahedi Kia 


\section{Introduction}

This article examines aspects of explicitation and implicitation on an attempt to find out The Effect of Implicitation \& Explicitation Strategies on the Acceptance of two different Farsi translations of George Orwell's Animal Farm. It seems that it has been first introduced by Vinay and Darbelnet (1958) who defined it as "the method of introducing into the TL clarifications/details which are implicit in the SL, but which become clear from the context or the situation". Explicitation has been seen as an inherent feature of the process of translation, e.g., by Blum-Kulka (1986), "according to which translations are always longer than the originals, regardless of the languages, genres and registers concerned" (Klaudy 1998, p. 84). This hypothesis has been further explored by i.a. Klaudy and Károly (2005) and Pápai (2004). Explicitation has also been considered in the context of the strategies used by both non-professional and professional translators (Laviosa-Braithwaite 1996; Puurtinen 2003; Dimitrova 2005a and b). Implicitation seems to be a less frequent procedure (Klaudy and Károly 2005). Also Explicitation is one of the hypothesized universals of translation posited by Mona Baker but the problem is that the translations I have considered the number of words in translation was less so it was my hypothesis that in Persian translations being universal seemed to be true for Persian translations.

My key point of interest in this article is to explore the explicitation hypothesis in the context of literature and novel translation. Because of the specific functions of literary texts, translations made by the two translators of this work may be assumed not to comply with the explicitation hypothesis and it is mostly translator oriented.

\section{Literature Review}

Translation Studies (TS), starting as a sub-discipline of traditional linguistics, philology and literature studies, has developed into and become legitimated as an independent academic discipline over the last four decades (Neubert and Shreve, 1992). Descriptive translation studies (DTS), mentioned by Holmes $(1972,1988)$ as a branch of the discipline, constantly maintains close contact with empirical phenomena (Neubert and Shreve, 1992) and has been invigorated by new ideas from disciplines such as cognitive science, information science and psycholinguistics, to name just a few. Having abandoned the concern with exclusively linguistic issues and embraced ideas and methodologies on an interdisciplinary basis, research in translation studies has shifted its focus from the text and translation product to the translator and translation process. These two major approaches have been designated by Holmes $(1972,1988)$ as product-oriented and process-oriented research.

Product-oriented DTS focuses on the description or comparative and contrastive analysis of translation products. It is based on describing the features of individual translations or comparing the similarities or differences between the source text (ST) and target text (TT), or the multiple TTs produced by different translators from the same ST (Holmes 1972, 1988). Corpus-based translation studies, started by Mona Baker (1995) and Sara Laviosa (1998), are the representative product-oriented DTS that have used new technologies since the late twentieth century. Facilitated by the linguistic analysis of a large number of electronically stored texts and using computer-assisted tools and programs, they examine the features of 
translations, such as explicitation, simplification, normalization/conservatism and leveling out (Baker, 1996). Corpus-based studies nevertheless make assumptions about the nuances of certain translation features and strategies based solely on the texts, without any support from process-based empirical data.

Process-oriented DTS emphasizes the translation process itself: namely, what is happening in the "black box" of the translator's mind as he or she conducts a translation task (Holmes 1972, 1988). Inquiries about how the ST is processed and comprehended, how the translation task is planned and conducted, and how the TT is produced and revised can all be registered and analyzed by certain process research tools and programs. The empirical data coming from the translation process provide greater validity to the searches on why some procedures or strategies in particular are employed by translators and how certain features of translation emerge. Process-oriented DTS enlists the fruits of computer science, cognitive science, psycholinguistics, cultural studies and sociology, and tries to reflect the interdisciplinary nature of translation studies.

Translation is a cognitively complex text processing and producing task. Its primary procedures include processing the ST, task planning and producing the TT: the translator's cognitive activities and subjectivity; his or her comprehension of the ST; regard for the target language readers and the situation in which the translation is completed; professional experience and the ability to use tools and aids; all of these have considerable effect on TT production. Other factors, such as socio-cultural views and concepts as well as ideological differences, also influence the production of the TT and its acceptability in the TL culture. The translation product, on the other hand, is "tangible evidence of the translation process that precedes it and leads to it" and, as such, adds validity to the study of the translation process (Dimitrova, 2005: 3). This integrated quality of the task of translation strongly suggests that researchers should consider the texts, process and translators as one rather than as separate entities.

Translation theories, as Neubert and Shreve (1992) point out, should be based on the observation of actual translation practice and behavior with the support of solid, specific data: "When theory is divorced from the observation of reality, then confusion and ambiguity arise" (1992). They further claim that "translation studies should describe the ways that translators respond to variability in the translation situation... and explain actual translation products" (1992). Although over the past two decades, process-oriented translation research has attracted increasing interest among translation researchers and scholars, it still, according to Jääskeläinen (2000), "may lack the explanatory power required to draw reliable generalizations which are necessary for building viable theories and creating testable hypotheses." (P.72) To fully understand certain phenomena in translation, mere descriptions are not enough; we need to dig more deeply into the translator's motivations for using certain strategies and the relations between a translation and the translator's cognitive activities. Only by working from the empirical data of the translation process and product can we form hypotheses as to what is happening in the translator's mind and as to why and how certain specific decisions are made in the translation process. 


\section{Al Macrothink}

International Journal of Linguistics

ISSN 1948-5425

2021, Vol. 13, No. 5

Explicitation is a translation feature which has received a lot of attention in studies of translation. It seems to have been first introduced by Vinay and Darbelnet (1958) who defined it as "the method of introducing into the TL clarifications/details which are implicit in the SL, but which become clear from the context or the situation" (p.9, translated from French by Dimitrova, 2005, p.34). One specific type of explicitation which has been observed in several studies is the explicitation related to the shifts of cohesion through translation. The first systematic study in this regard is associated with Blum-Kulka's (1986) work. Blum-Kulka takes a discoursal and communicative approach to the study of translation and argues that the process of translation necessarily entails shifts both in textual and discoursal relationships. She points out that these shifts occur on two levels, i.e. cohesion and coherence.

On the level of cohesion, shifts in types of cohesive markers used in translation seem to affect translations in terms of level of explicitness and text meaning. Shifts in the levels of explicitness are partly related to grammatical differences between languages and differences in stylistic preferences for types of cohesive markers and partly related to the process of translation. Based on the latter part, i.e. the process of translation, Blum-Kulka formulates "the explicitation hypothesis," which postulates "an observed cohesive explicitness from ST to TT regardless of the increase traceable to differences between the two linguistic and textual systems involved" (p.300).

Among the explicitations that occur through shifts of cohesion in translation is the explicit expression in the TT of logical links that are implicit in the ST. As there are few studies regarding this type of explicitation in Persian-English translation, the present research is an attempt to study Eexplicitation and implicitations that occur in two different translations to scrutinize the number of their occurrence in both translations and their effect on the cohesion of the TT, and the possible reasons behind their occurrence in the TT.

\section{Theoretical Framework}

For better understanding the method of explicitation, we offer some useful insights into process of translation and teaching.

Klaudy's model (1996 and 1998):

Obligatory explicitation

Optional explicitation

Pragmatic explicitation

Translation-inherent explicitation

Vahedi Kia's model (2011):

Addition of cultural information

Narrowing

Addition of conjunctions 


\section{Repetition}

\section{Specification}

\section{Addition of explanatory Vocabulary}

\section{Filling of elliptical constructions}

\section{Deduction}

\section{Extension of proper nouns}

\section{Disidiomatization}

\section{Methodology}

The researcher of the present study extracted data from George Orwell's Animal Farm. The researcher focused on two different translations of this novel. The translation had been done by two translators in Iran whose names are "Saleh Hosseini" and "Abbas Zarei".

In order to collect various instances of implimitation and explicitation, it was necessary to follow some procedures. Firstly, the sample of the study, i.e. the first chapter of the source text and its Persian translations, were analyzed for the instances of the implicitation and explicitation usage in both translations and then the found items were classified. The data in this study was analyzed and classified according to the models proposed by Klaudy (2008; previous version: 1998) and Vahedi Kia (2011), which primarily draws on Gumul's (2007) model.

Secondly, all the extracted cases of implicitation and explicitation were counted and the percentages of their usages were found. In this phase, all the sentences of both translations were analyzed and calculated. The determined instances of explicitation and implicitation in the translations of the ST were classified into the relevant types in a sort of table and the frequency of their occurrences was calculated and then the effect of the usage of each on the acceptance of the translated texts, were analyzed.

In order to analyze the collected data, the present study adopts both qualitative and quantitative analysis techniques. The analysis of the data was done by a comparative methodology of the source text with its equivalence translation in the target text. In order to achieve the objectives of the study, initially, number of words in Persian and English texts was counted in order to know how many words each contain. Then, both translated texts were analyzed based on the models proposed by Klaudy (2008; previous version: 1998) and Vahedi Kia (2011), which primarily draws on Gumul's (2007) to find out the frequency of the usage of implicitation and explicitation. After that the researcher compared the usage of these strategies in both translations and the frequency of each was inserted into a table. To evaluate the acceptance of the translations both translations were sent to five translators to choose between the two versions of the Persian translations. 


\subsection{Analysis of the Corpora}

An overall analysis of the data showed that the English text of George Orwell's Animal Farm has about $\mathbf{2 6 8 8}$ words but the first translation by Saleh Hosseini has $\mathbf{2 3 3 9}$ words and the second translation by Abbas Zarei has $\mathbf{2 5 2 5}$ words. This analysis showed that the overall number of words in both translations was less than the original text. The reading process of the novel leading to the comprehension of language and style of the source text was done to decide how to compare the source text with the translations. The translations were read to find out the style of the translations and the main strategies used to translate the source text. This analysis showed that the first translation by Saleh Hosseini tried to use older style of Persian writing but it was more faithful to the source text. On the other hand the other translation by Abbas Zarei had a more tangible language for the modern Persian reader but it had less loyalty to the source text. Another part of the analysis referred to the acceptance of the translations by the Persian translators. Both translations were given to 5 different translators to be read. Each one was supposed to choose which of them was more acceptable based on the following factors.

1. lexical choice

2. Natural language of the translation

3. Clarity

It is important to mention that both translators are among good and experienced translators in Iran but as there need to be a specific factor for our translators to choose based on a unified framework, the above mentioned framework was given to them to achieve unified results. It is also necessary to mention that none of the translators were aware of the name of translators. The whole text of each translation was divided into small parts and was given to the translators. They each were analyzed based on the above mentioned factors by the translators. Generally the analysis showed that two translators (Meisam Soleimani \& Amir Ahmadi) considered Saleh Hosseini's translation units more acceptable and three others (Nahid Kanpour, Davood Jahaniyan, and Iman Behzadpour) mentioned Abbas Zarei's translation units more acceptable. But the analysis of the corpora shows that 349 translation units by Saleh Hosseini are more acceptable by the translators but on the other hand 281 units of Abbas Zarei's translation units are more acceptable. The results showed that:

1-English-Persian translators used explicitation in an effort to make the target text more understandable than the source text but as a translator it seems that both translators mostly tried to transfer the meaning.

2- Abbas Zariee used 125 cases of explicitation and 161 cases of implicitation. On the other hand Saleh Hosseini used $\mathbf{1 2 6}$ cases of explicitation and only $\mathbf{7 6}$ cases of implicitation. Based on the above mentioned results it seems that there is no meaningful relationship between the usage of the strategies and the type of text. Based on the results Abbas Zariee used more cases of explicitation than Saleh Hosseini. On the other hand Saleh Hosseini used more cases of implicitation. Each of the Persian translators chose a different strategy to translate the units of the source text. Each translator has tried to transfer the meaning as well as possible. In 
other words it seems that usage of each strategy is translator-oriented and was just a matter of stylistic preference by the translator. The cases of implicitation and explicitation were at different levels and happened at the level of word, phrase, and sentence.

3- The most important thing related to the research corpora was that there was no clear connection between the number of cases each strategy was used and text type. We could see that Abbas Zariee used more implicitation for translating the first chapter of this novel than Saleh Hosseini. In other words it seems that usage of each strategy is translator-oriented and was just a matter of stylistic preference by the translator.

4- Three of our translators chose Saleh Hosseini's translation better. The results showed that both translations are good enough, but what is clear is that Iranian translators chose the units that used more explicitation strategy.

\section{Results and Discussion}

The analysis of the data proceeded as follows:

The whole corpus was read multiple times. Explicitations and implicitations were identified manually according to the frameworks. The findings indicated that, usage of implicitation and explicitation cases by the translators could mostly be divided into the following classifications. Additions to translations to transfer the meaning better, omissions of the translations which could have several reasons and I will talk about them more, and also there were some usages of substitutions of nouns, pronouns, proper names, adjectives, adverbs, and connectives which were sometimes optional and sometimes necessary. But the most important thing related to the research corpora was that there is no clear connection between the number of cases each strategy was used and text type. We can see that Abbas Zariee used more implicitation for translating the first chapter of this novel but on the other hand Saleh Hosseini used explicitation cases more than implicitation. In other words it seems that usage of each strategy is translator-oriented and was just a matter of stylistic preference by the translator. Various kinds of shifts were analyzed in this study but analysis of some shifts was too complex in the context of the present study. For example the translation of the song of this chapter clearly warrants a detailed study of their own. The researcher analyzed this part based on some social factors like semantic difference, pragmatic difference and poetic language the source and target language. Also the present study departed from the basic assumption that every instance of explicitation and implicitation has a distinct cause (e.g. cultural filtering, risk avoidance, etc.)

As it was shown in appendix 1 the other important result in the study with regard to the cases of explicitation and implicitation usage is that; three of our translators chose Saleh Hosseini's translation better. The results show that both translations are good enough, but what is clear is that Iranian translators chose the units that used more explicitation strategy.

Another point which seems to be important to mention is that the models of Vahedi Kia and Klaudy were only used as a framework to distinguish explicitation from implicitation. Little by little throughout the study it became clear they both have some shortcomings and sometimes failed to determine if the unit used implicitation or explicitation. In addition to 
that when dealing with finding out the strategies used in poems it seems to be difficult to distinguish the type of strategy used and there need to be a more comprehensive framework that considers both explicitation and implicitation.

\section{Conclusion}

The present study also has shown that translators explicitate and implicitate for many different reasons. In sum, translators tend to explicitate.

- If they feel that a coreference relation implicitly given in the source text is not easily inferable (which may lead to processing difficulties)

- If they feel that the antecedent of a coreferential expression is not easy to identify (which may lead to processing difficulties).

- If the target language offers a lexical item that suits the context at hand but is not available in the source language.

- If the target language offers a syntactic slot unavailable in the source language that lends itself to being filled (e.g. by a connective).

- In order to comply with typical communicative preferences of target language readers.

- Following a general strategy of maximizing explicitness in order to minimize the risk of misunderstanding.

- If they feel that a coreference relation explicitly given in the source text will be easily inferable if it is verbalized less explicitly or not verbalized at all.

- If a particular lexical item in the source text has no equivalent in the target language.

- If the target language lacks a syntactic slot offered by the source language.

- In order to comply with typical communicative preferences of target language readers.

- To avoid stylistic awkwardness.

- To achieve a neat information structure, i.e. a distribution of given and new information that secures optimal processing in the target language.

Another important matter is the relationship between acceptance and the usage of explicitation and implicitation. Based on the results of the study it seems that three of our translators chose Saleh Hosseini's translation better. In other words based on the results it seems that both translations are good enough, but what is clear is that 5 Iranian translators of the study chose the units that used more explicitation strategy more preferable which shows a tendency to use explicitation strategy among Persian translators.

\subsection{Implications of the Study}

The findings of the present study may provide some insights for EFL Iranian students. Also, translators, to comprehend better the text meanings and text structures via a comprehensive review of conjunctions in both English and Persian. By finding evidences for the number of 
explicitation and implicitation in translations of this study, it is implied that explicitation is not a universal feature of all texts but rather a matter translator style and choice. Therefore, both implicitation and explicitation need more investigation. Based on the results of the study as all of the textual elements may undergo implicitation and explicitation it seems necessary to have a model to analyze the number of explicitation and implicitation cases, this point is implied that not all textual elements could be accounted for through all models.

This means that some models only account for function words like conjunctions and some only account for content words. In addition, as the results and my investigation indicated explicitation can be automatic, i.e., not all the times translators explicitate, but it is performed unconsciously or while translation, the translation itself, as a rewriting process, rewrites the elements and leads to explicitation.

Further, it is implied from the results that meaning and message of all conjunctions might not be quite similar in all languages, especially, Persian and English. Explicitation and implicitation can lead to a more natural and understandable target text if be used efficiently, while haphazard usage of them may lead to redundancy and meaning distortion.

\subsection{Suggestions and Implication}

As the researcher started data analysis chapter I faced the difficulty of distinguishing explicitation and implicitation in the translation units I felt a necessity to have a step by step procedure to analyze a translation. I think this analysis needs to be based on a procedure and also it is necessary to consider the priorities. Based on the experience of this study we could see that the occurrence of explicitating and implicitating shifts is determined by lexical, syntactic, semantic, and stylistic differences in the source and target text. I recommend the following procedures to analyze a translation.

The first step is to divide a translation into smaller parts that could be called translation units. A unit could be a sentence or combination of sentences that are in some ways related to each other regarding meaning and structure. The important point here is that these units should be as short as possible. We can call this step "unit division".

Step two in this procedure is the analysis of the number of implicitation and explicitation used based on the lexical features.

In the following examples you can see this step in practice.

Word had gone round during the day that old Major, the prize Middle White boar, had had a strange dream on the previous night and wished to communicate it to the other animals.

شايعه شده بود مِيجِر بِير، برنده جايزه خوك سفيد، شب يِش خو ابى ديده كه مى خواهد آن را با حيو انات ديكر مزر عله در ميان بكذارد.

In this part we see the translation of "to communicate" as "در ميان بكذارد" which is a case of lexical explicitatiation.

At the last moment Mollie, the foolish, pretty white mare who drew Mr. Jones's trap, came mincing daintily in, chewing at a lump of sugar. 
در آخرين لحظه مولى، ماديان سفيد و زيباو خُل و جِل، در حالى كه قند ميخورد، با ناز و ادا وارد شد. كار او كثيدن درشكه آقاى جونز بود.

Here we can see a case of lexical implicitation. To translate "foolish" he chose to translate it as "خُل و جِل which is a case of lexical implicitation.

Step three in this procedure is the analysis of the number of implicitation and explicitation used based on the syntactic features. In the following examples you can see this step in practice.

She took a place near the front and began flirting her white mane, hoping to draw attention to the red ribbons it was plaited with.

در محلي نسبتا جلو نشست و مشغول وررفتن با بال سفيدش شد، به اين اميد كه به روبان قرمزي كه به آن بافته شده بود

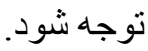

In this part the translator changed the structure of the translation and translated "red ribbons it was plaited with" as "روبان قرمزي كه به آن بافته شده بود". Here the difference between the source and target text is oblivious in terms of syntax and the translator used syntactic explicitation by adding "كه" to his translation.

All the animals were now present except Moses, the tame raven, who slept on a perch behind the back door

جز موزز زاغ اهلي كه برشاخه درختي يشت در خو ابيده بود همه حيو انات حاضر بودند.

In this part we can see the usage of syntactic implicitation.

Step four in this procedure is the analysis of the number of implicitation and explicitation used based on the semantic features. In the following examples you can see this step in practice.

Let us face it: our lives are miserable, laborious, and short.

بايد اقرار كرد كه حيات ما كوتاه است، برمشقت است و نكبت بار است.

Here the translator used implicitation by translating "Let us face it" as "بايد اقرار كرد". This translation uses semantic implicitation.

But I will come to the dream later. I have something else to say first.

خواب رو بعدا براتون تعريف مى كنم. اول مى خوام درباره جيز ديعه اى باهاتون حرف بزنم.

تعريف مى " In this example we see the usage of semantic explicitation by translating "come" as كن" which is a case of change in meaning.

Step five in this procedure is the analysis of the number of implicitation and explicitation used based on the stylistic features. In the following examples you can see this step in practice.

He passed away some years later. 
جند سال بعد به درك و اصل شد.

"بعد به درك واصل شد" "بse we see the usage of explicitation. He translated "passed away" as which is a case of stylistic explicitation. In the translation the translator used a more informal style of language to transfer the meaning.

He kicked the bucket.

more.

Here we see the usage of implicitation. The translator translated "kicked the bucket" as " فوت ش”' which is a case of stylistic implicitation. In the translation the translated used a formal style of language to transfer the meaning.

\subsection{Suggestions for Further Research}

This study, its results, models, framework, and methodology provided insights to offer some useful suggestions to further research in the same field and other interdependent fields of study. The analysis of translations from English into Persian based on implicitation and explicitation may lead to more useful results and insights. Therefore, other researchers are recommended to select other literary sources and adopt models used in this study to examine implicitation and explicitation. Translating conjunctions could be investigated separately based on the recommended model. Further, another research could investigate cohesive markers in Translation Studies (TS); i.e., to see the way cohesive markers is translated to find out which strategy is used more and why. Besides, conjunctions could be investigated based on the recommended strategy of this study. They could be tested to see how much they contribute to the communicativeness of any text. Moreover, as there are different models of error analysis, the research could be furthered by performing error analysis on the translation of to see which translation was more successful in a comparative manner. In addition, as translators of this novel chose different ways of translations, other researchers could take advantage and explore the translation strategies and error analysis in comparison to each other. Furthermore, since translators come across difficulties in the analysis of the usage of explicitation and implicitation, the investigation of difficulties faced by translators in the analysis of these strategies could contribute to the field of translation strategies and is a topic of research to achieve better models for the analysis of translations from English into Persian. Another study could be investigated in terms of the function of each strategy on the translation across Persian and English, or vice versa. The researcher also recommends studying the usage of implicitation and explicitation strategies on the dubbing and subtitling of movies.

\section{References}

Bada, E. (2000). Culture in ETL. Cukurova University Journal of Social Sciences (6), 100-110.

Bahous, R., Bacha, N., \& Nabhani, M. (2011). Motivating Students in the EFL Classroom: A Case Study of Perspectives. English Language Teaching, 4(3). https://doi.org/10.5539/elt.v4n3p33 


\section{Macrothink}

International Journal of Linguistics

ISSN 1948-5425

2021, Vol. 13, No. 5

Bahrani, T. (2013). Importance of language input in language learning. International Research Journal of Applied and Basic Sciences, 6(10), 1376-1379.

Bahrani, T., \& Sim, T. S. (2012). Audiovisual News, Cartoons, and Films as Sources of Authentic Language Input and Language Proficiency Enhancement. Turkish Online Journal of Educational Technology - TOJET, 11(4), 56-64.

Berardo, S. A. (2006). The use of authentic materials in the teaching of reading. The Reading Matrix, 6(2), 60-69.

Bernardo, A. S. (2011). Reading what's beyond the textbooks: Documentary films as student Projects in college reading courses. ELT WorldOnline.com, 3, 1-12.

Blum-Kulka, S. (1986). Shifts of Cohesion and Coherence in translation. In Juliane H., \& Shoshana B-K. (Eds.). Interlingual and intercultural communication (pp. 17-35). Tubingen: Gunter Narr Verlag.

Brown, H. D. (1994). Principles of Language Learning and Teaching. Englewood Cliffs, New Jersey: Prentice Hall Regents.

Brown, S. K. (2010). Popular films in the EFL classroom: Study of methodology. Procedia -Social and Behavioral Sciences, 3, 45-54. https://doi.org/10.1016/j.sbspro.2010.07.011

Caroline, C. A. O. (2007). Authentic documents in the teaching and learning of a foreign language. Journal of Language, Technology \& Entrepreneurship in Africa, 1(1), 25-33.

Celce-Murcia, M. (2001). Teaching English as a second or foreign language. Boston: Heinle \& Heinle.

Hibbing, A. N., \& Rankin-Erickson, J. L. (2003). A Picture Is Worth a Thousand Words: Using Visual Images To Improve Comprehension for Middle School Struggling Readers. Reading Teacher, 56(8), 758-770.

Iranmanesh, A., \& Darani, L. H. (2018). Effects of Movies and Gender on Learning English Idiomatic and Everyday Expressions among Iranian EFL Learners. Malaysian Online Journal of Educational Sciences, 6(3), 1-11.

Ismaili, M. (2013). The Effectiveness of Using Movies in the EFL Classroom - A Study Conducted at South East European University. Academic Journal of Interdisciplinary Studies, 2(4), 121.

Kabooha, R. H. (2016). Using Movies in EFL Classrooms: A Study Conducted at the English Language Institute (ELI), King Abdul-Aziz University. English Language Teaching, 9(3), 248-267.

Kaiser, M. (2009). Teaching With Film Clips. Teaching Language and Culture with Film. University of California, Berkeley. 15-18 June 2009. Presentation.

Kalra, R. (2017). The Effectiveness of Using Films in the EFL Classroom: A Case Study Conducted at an International University in Thailand. Arab World English Journal, 8(3), 
289-301. https://doi.org/10.24093/awej/vol8no3.19

Keene, M. D. (2006). Viewing video and DVD in the EFL classroom. Bunkyo Gakuin University Journal, 8(1), 217-234.

Kessler, G. (2013). Teaching ESL/ EFL in a World of Social Media, Mash-Ups, and Hyper-Collaboration. TESOL Journal, 4(4), 615-632. https://doi.org/10.1002/tesj.106

King, J. (2002). Using DVD feature films in the EFL classroom. ELT Newsletter, 88. Retrieved form http://www.eltnewsletter.com/back/february2002/art882002.htm

Klaudy, K. (1998): Explicitation. In Mona B., \& Kirsten M. (Eds.), Routledge Encyclopedia of Translation Studies (pp80-85). London: Routledge.

Klaudy, K., \& Karoly, K. (2005). Implicitation in translation: empirical evidence for operational asymmetry in translation. Across Languages and Cultures, 6(1), 3-28.

Kramsch, C., \& Sullivan, P. (1996). Appropriate pedagogy. ELT Journal, 50(3), 199-212. https://doi.org/10.1093/elt/50.3.199

Krashen, S. (2011a). The Compelling (not just interesting) Input Hypothesis. The English Connection. A Publication of KOTESOL. 15(3). Retrieved from http://www.koreatesol.org/sites/default/files/pdf_publications/TECv15n3-11Autumn.pdf

Krashen, S. D. (1982). Principles and practice in second language acquisition. Oxford: Pergamon.

Krashen, S. D. (1985). The input hypothesis: issues and implications. London: Longman.

Krashen, S., \& Bland, J. (2014). Compelling Comprehensible Input. Academic Language and School Libraries, 2(2), 12.

Li, X., \& Wang, P. (2015). A research on using English movies to improve Chinese College students' oral English. Theory and Practice in Language Studies, (5), 1096.

Long, Q. (2003). A study of teaching English listening and speaking through films. Media in Foreign Language Instruction, 3, 1-10.

Lunin, M., \& Minaeva, L. (2015). Translated Subtitles Language Learning Method: A New Practical Approach to Teaching English. Procedia - Social and Behavioral Sciences, 199, 268-275. https://doi.org/10.1016/j.sbspro.2015.07.516

Macwan, H. J. (2015). Using visual aids as authentic material in ESL classrooms. Research Journal of English Language and Literature (RJELAL), 3(1), 91-96.

Maroko, G. M. (2010). The authentic materials approach in the teaching of functional writing in the classroom. Japan: Rudolf Reinelt Research Laboratory EU Matsuyama.

McGrath, C. (2016). Film in action: Teaching language using moving images. English Australia Journal, (2), 108.

Morley, H. J., \& Lawrence, M. S. (1971). The Use of Films in Teaching English as a Second 
Language1.

Language

Learning,

21(1),

117-117.

https://doi.org/10.1111/j.1467-1770.1971.tb00495.x

Ockert, D. (2015). Skype-Based English Activities: A Case for Compelling Input? Correlational Changes before and after Skype Exchanges. Teaching English with Technology, 15(3), 47-60.

Papai, V. (2004). Explicitation: A universal of translated text?. In Anna M. (Ed.), Translation Universals. Do They Exist? (pp. 143-164). Amsterdam: John Benjamins.

Park, Y., \& Jung, E. (2016). Exploring the Use of Video-clips for Motivation Building in a Secondary School EFL Setting. English Language Teaching, 9(10), 81. https://doi.org/10.5539/elt.v9n10p81

Sherman, J. (2003). Using Authentic Video in the Classroom. Cambridge: Cambridge University Press.

Shu-Qing, S. (2009). Opinions and comments of cram schools' teachers' and students' preferences on using six authentic materials activities in the Cram Schools in Taiwan. Retrieved from http://ir.lib.au.edu.tw/bitstream/987654321/2618/1/CH10-conf.2009_su02_01.pdf

Sirmandi, E. H., \& Sardareh, S. A. (2016). The Effect of BBC World Clips with and without Subtitles on Intermediate EFL Learners' Vocabulary Development. Malaysian Online Journal of Educational Sciences, 4(4), 61-69.

Soh, G. E., \& Kaur, H. (2007). The use of films to promote critical thinking in the English language. In C. Tan (Ed.), Engaging films \& music videos in critical thinking (pp. 139-153). Singapore: McGraw-Hill.

Soong, D. (2012). Using documentary films in oral interpretation class what is the appropriate length?. International Journal of Applied Linguistics \& English Literature, 1(6), 131-141.

Stewart, D. M. (2006). Film English: Using Films to Teach English. Electronic Journal of English Education, 24.

Tg Abdul Rahman, T. A. F., Chik, A. R., Sahrir, M. S., \& Nordin, M. S. (2017). A Review of Documentary Film as Authentic Input in Enhancing Writing Skills in ASL Setting. Journal of Nusantara Studies (JONUS), 2(1), 99. https://doi.org/10.24200/jonus.vol2iss1pp99-110

Tognozzi, E. (2010). Teaching and evaluating language and culture through film. Italica, (1), 69.

Tuncay, H. (2014). An Integrated Skills Approach Using Feature Movies in EFL at Tertiary Level. The Turkish Online Journal of Educational Technology, 13(1), 8.

Wiggins, G., \& McTighe, J. (2005). Understanding by design. USA: Association for Supervision and Curriculum Development. 


\section{Macrothink}

International Journal of Linguistics

ISSN 1948-5425 2021, Vol. 13, No. 5

Yu, K. F. (2009). Learning English through films: a case study of a Hong Kong class. Thesis, University of Hong Kong, Pokfulam, Hong Kong SAR. Retrieved from https://doi.org/10.5353/th_b4324124

Zhang, Q. (2013). The impact of film and film-based activities on the attitudes of EnglishSpeaking secondary-school students towards L2 Chinese. Journal of Creative Practices in Language Learning and Teaching (CPLT), 1(2), 1-17.

\section{Copyrights}

Copyright for this article is retained by the author(s), with first publication rights granted to the journal.

This is an open-access article distributed under the terms and conditions of the Creative Commons Attribution license (http://creativecommons.org/licenses/by/4.0/) 